\title{
A FORMAÇÃO HISTÓRICA DO RIO GRANDE DO SUL. O INDÍGENA NO DISCURSO LUSO-BRASILEIRO
}

\author{
Luiz Henrique Torres*
}

A formação histórica do Rio Grande do Sul vem recebendo releituras e revisões críticas das principais orientaçães presentes na produção historiográfica ao longo dos séculos XIX e XX.

$\mathrm{O}$ encaminhamento metodológico dos intelectuais gaúchos, tantas vezes, orientou-se pela ausência de autocrítica e fundamentou-se no privilegiamento de personagens, grupos étnicos, acontecimentos ou períodos. Nas "histórias" escritas a partir da ênfase nos portugueses, açorianos, jesuítas etc., constata-se o parcelamento de uma totalidade mais ampla que o processo humano no tempo no atual Rio Grande do Sul, e, este processo, não pertence a uma etnia ou alguns personagens, mas um somatório de experiências que constitui nossa memória social.O pressuposto ligado às teleologias historicistas que estabelecem $a$ priori um movimento linear do acontecer histórico, acaba por promover um esvaziamento do espaço - destituindo-o de seu passado e da historicidade dos grupos que ali viveram ou vivem - desencadeando a elaboração artificiosa de um novo espaço definido a partir de interesses que privam a dimensão de dinamicidade. Citando dois exemplos destas teleologias: a experiência civilizatória que desencadeada com a primeira

* Departamento de Biblioteconomia e História da Universidade do Rio Grande. 96201-900 Rio Grande-RS. 
Redução jesuítico-guarani fundada por Roque Gonzales em 1626 (cuja ação centrada, por estes autores, na atuação dos missionários jesuítas), a colonização e fundamento da "brasilidade", após a fundação do Presídio de Jesus Maria por Silva Pais em 1737 (lançando as bases do universo português). Neste texto, serão destacados discursos historiográficos que convergem para a formação lusitana e a decorrente formulação de representações que recairão sobre os indígenas.

\section{TEMPO E ESPAÇO}

Nos discursos luso-brasileiros ao longo das décadas de 1930-60, o espaço esvaziado das populaçōes indígenas e é redefinido: supostamente delimitado em suas fronteiras desde os primórdios da ocupação portuguesa como se houvesse um "destino manifesto" - historicamente, a delimitação territorial somente se concretizaria no século XIX, através de ações diplomáticas e militares, motivadas por interesses econômicos e políticos -, pressupondo que o gaúcho sul-rio-grandense sempre foi militante do "espírito de brasilidade" e lutou por aversão ao que vinha do Prata, como um sentimento inato de repulsa a tudo o que não fosse de tradição luso-brasileira - nos séculos XVII, XVIII e XIX, realmente existiu este componente metafísico perfeitamente desenvolvido entre a população brasileira?

A definição da relação Brasil-Rio Grande do Sul nega a inserção deste território num processo histórico complexo ocorrido na Bacia Platina Oriental. A fragmentação política e ideológica do Rio Grande do Sul frente a esta paisagem técnica e fisiográfica platina, ocorreu por motivaçôes ligadas a formação histórica dos países desta região, cujos fatores serão somente sugeridos, como o caso da intervenção britânica no incremento a conflitos que conduziram a fragmentação política no Prata, a economia pecuária do Rio Grande do Sul concorrente com o Uruguai e Argentina teve seu direcionamento para o Brasil e não para o extremo sul; o recurso colonial e imperial à militarização e antagonismo com os países de formação espanhola, enfim, outros fatores além de ordem étnica (espanhóis, portugueses) ou metafísicos (brasilidade inata) devem ser considerados na constituição das nacionalidades platinas. 
Interessa ao historiador, pensar a Bacia Platina num nível que supere um quadro estático das atuais delimitações oriundas dos conflitos das frentes de expansão luso-brasileira e espanhola-americana e perceber uma história mais longa, que desconheceu os antagonismos ibéricos exportados para um Novo Mundo na acepçâo dos europeus.

Esta duração está relacionada a temporalidade dos arqueólogos da Pré-História, isto é, os milênios que antecedem a chegada dos europeus na América. No caso do Rio Grande do Sul, a ocupação humana inicia a mais de doze mil anos antes do presente com a chegada de caçadores-coletores que convivem com a megafauna pleistocênica. No holoceno, a diversidade do povoamento amplia-se nos campos, planalto, litoral e regiōes alagadiças.

A cerca de dois mil anos, os guaranis trazem inovações técnicas e distribuem-se nas margens férteis dos rios, entre a mata subtropical onde praticam a horticultura. No planalto, os construtores de casas subterrâneas desenvolvem adaptações para as baixas temperaturas enquanto, nas margens das lagoas dos Patos, Mirim e Mangueira, populações vivem da pesca e da caça dos animais das áreas alagadiças do sul.

O quadro arqueológico apresenta diversidades de adaptaçōes a ecossistemas diferenciados. Os dados etno-históricos de cronistas lusos e padres jesuítas, demonstram a ocupação dos grandes rios e do planalto por populações indígenas no período histórico. Categorias interpretativas como "terra de ninguém" tẫo difundida no meio intelectual, acoberta a diversidade de experiências vivenciadas, em outras palavras, modalidades de civilização européia representam somente $3 \%$ da cronologia da história das sociedades em nosso Estado.O espaço geográfico despojado de continuidade e de ocupação por sociedades indígenas, sendo redefinido e delimitado pela pulsação geopolítica dos tratados e açōes militares européias. A diplomacia de negação da existência social do "outro", num universo escravagista de políticas indigenistas contraditórias e de interesses político-econômicos ligados a partir do discurso da ausência do indígena ou sua sobrevivência em alguns costumes e hábitos da peonada campeira.

Negação, fragmentação e incorporação, sâo etapas na construção intelectual de um espaço luso-brasileiro cadenciado por um destino histórico legitimado nas representações que caracterizam o gaúcho, ordeiro e disciplinado. Na tríade da formação técnica, moral e política, um Rio Grande do Sul: português; heróico e democrático. 
A fragmentação do processo histórico induz a compreensão de que a expansão ultramarina européia, promovedora da "descoberta ibérica" do Continente Americano, forjou-se como universo civilizatório referencial para delimitar a primitividade e o progresso das sociedades aqui estabelecidas. Lembremos que o colonialismo europeu posterior ao século XV, que já completou 500 anos, representa $1 \%$ do tempo de ocupação deste continente. Os $99 \%$ da história anterior da América, é ainda pouco conhecida e desenrolou-se por cerca de 50 mil anos. A transitoriedade acompanhou estas sociedades, como o modo-de-ser caçador que perdurou por dezenas de milênios. O que dizer da recente colonização européia de 5 séculos (cuja compreensão é indispensável para equacionarmos problemas atuais), ou das sociedades industriais com cerca de 200 anos de revolução tecnológica: serão os referenciais que esgotam um acontecer histórico americano e rio-platense muito anterior, numa multiplicidade de experiências culturais e com distintos conceitos de natureza?

As categorias analíticas de fragmentação e temporalidade ocidental, precisam ser repensadas com base em conceitos como totalidade e transitoriedade. Respostas para "de onde viemos e qual o sentido para o presente" passam pelo resgate do processo histórico e pela relativização dos referenciais eurocêntricos que devem ser mediados por um instrumental metodológico ligado à História, Arqueologia, Geografia e demais campos do conhecimento. No aprofundamento em busca da totalização do acontecer poderíamos encontrar respostas mais satisfatórias sobre o lugar de nossa civilização pós-Descoberta européia nesta transitoriedade.

\section{PARADIGMA HISTORIOGRÁFICO}

O fundamento epistemológico da história (conhecimento) pode ser analisado a partir da produção intelectual e sua construção teóricometodológica. O desvelamento das representações vinculadas nos conceitos possibilita uma leitura com base na crítica historiográfica, isto é, o arrolamento, sistematização e crítica da historiografia. As palavras história e historiografia, decorrente de seus múltiplos sentidos (polissemia) e pelo, tantas vezes ausente dimensionamento epistemológico. 
Neste artigo, entende-se por História o processo humano no tempo (acontecer) e história o conhecimento ou produção intelectual sobre aquele acontecer. A historiografia corresponde ao conhecimento histórico produzido sobre certo tema em determinado período. A crítica historiográfica situa este conhecimento no contexto que lhe deu origem e sentido constituindo-se numa recriação histórica, um processo de revisão e produção do conhecimento na historicidade das motivações no presente.

A preocupação em dar sentidos para a produção historiográfica passa pela leitura dos pressupostos epistemológicos desta, e classificação em unidades discursivas maiores que são os paradigmas, entendidos neste contexto como o complexo de postulados, conceitos e procedimentos mínimos que distinguem, pela maior ou menor adesão dos autores da área, um enfoque de outro no seio da problemática epistemológica da história ${ }^{1}$. O paradigma epistemológico refere-se ao complexo metodológico na produção do saber histórico e que possibilita a identificação de uma unidade discursiva, enquanto o paradigma ou corrente historiográfica é definido na fundamentação teórico-metodológica do conhecimento histórico produzido por determinada comunidade intelectual com base em paradigmas epistemológicos. No caso da produção historiográfica do Rio Grande do Sul nas décadas de 1930 a início dos anos sessenta, os fundamentos dominantes são o historicismo e o positivismo. A unidade discursiva destas correntes reside no relato causal, linear, sincrônico, fatos episódicos, tempo breve, elementos afinados com a análise positivista e que perspassam sistematicamente as obras. $\mathrm{O}$ historicismo está presente no encaminhamento teleológico, no recurso narrativo linear e na recriação de cadeias de acontecimentos onde as sociedades dinamizam-se segundo expressões deterministas, de orientação divina ou dentro de uma lógica histórica².

Nesta direção, denomino de paradigma historiográfico tradicional os elementos positivistas e do historicismo que apresentam uma convergência discursiva nos estudos sobre a formação histórica do Rio Grande do Sul.

O paradigma historiográfico tradicional esclarece sobre as modalidades e análises desta intelectualidade para a elaboração dos métodos do conhecimento. A compreensão na dinâmica histórica, debates e antagonismos, requer a introdução do conceito de tendência historiográfica, 
ou seja, os enfoques que privilegiam determinados temas, personagens, períodos, conjunturas ou análises. Duas tendências polarizam os debates no período anteriormente indicado a tendência da formação missioneira com recorrência a explicação histórica voltada a teleologia divina, e a tendência luso-brasileira que prende-se a ênfase no universo português e brasileiro e na crença de uma teleologia que funda-se numa "lógica histórica” da brasilidade para explicar a formação do Rio Grande do Sul.

\section{HISTORIOGRAFIA LUSO-BRASILEIRA}

A produção intelectual luso-brasileira ${ }^{3}$ no Rio Grande do Sul projetou sobre $o$ indígena uma série de representações que podem ser problematizadas. Serão indicados alguns discursos desta tendência historiográfica no período que inicia na década de 1930 até meados dos anos 1960, questionando o etnocentrismo dos autores ao abordar a participaçāo do indígena nesta formação.

Para os intelectuais da tendência historiográfica luso-brasileira onde serão destacados João Borges Fortes ${ }^{4}$, Souza Docca ${ }^{5}$, João Pinto da Silva ${ }^{6}$, Walter Spalding ${ }^{7}$, Amyr Borges Fortes ${ }^{8}$, Othelo Rosa ${ }^{9}$, Moysés Vellinho ${ }^{10}$, Arthur Ferreira Filho ${ }^{11}$, Carlos Dante de Moraes ${ }^{12}$ e Félix Contreiras Rodrigues ${ }^{13}$, a diretriz seguida é a de demonstrar que o Rio Grande do Sul é "indiscutivelmente" marcado pela formação portuguesa e desde os primórdios da ocupação, a população luso-brasileira combateu, com plena consciência histórica de fazer parte deste universo, os interesses espanhóis-missioneiros quando da disputa pela delimitação da fronteira sul do Brasil.

Inicialmente, cabe destacar o etnocentrismo presente nestes discursos. Considera-se, como propõe Norma Telles ${ }^{14}$, que o etnocentrismo denota a maneira pela qual um grupo identificado por sua particularidade cultural constrói uma imagem do universo que favorece a si mesmo. Compõe-se de uma valorização positiva do próprio grupo e uma referência aos grupos exteriores marcada pela aplicação de normas do seu grupo, ignorando, portanto, a possibilidade do "outro" ser diferente. Destituído de uma validade racional, o etnocentrismo está difundido, em diferentes níveis, em todas as culturas humanas. Concomitante ao fato de preferir a própria cultura desenvolve-se um preconceito acrítico em favor. 
do próprio grupo e uma visão distorcida e preconceituosa em relação aos demais.

Os autores referidos compartilham desta visão etnocêntrica onde a sociedade do "eu" (no caso, luso-brasileira) é superior, - espaço da cultura e da civilização por excelência - onde existe o saber, o trabalho, o progresso; a sociedade do "outro" (indígena) é atrasada, espaço da selvageria e da barbárie, onde a confusão, a desarticulação e a desordem são constantemente evocadas. A civilização luso-brasileira acaba por constituir-se como o referencial que conduz um discurso etnocêntrico que se afirma científico e neutro. Desta forma, o processo histórico, se reduz à participaçẫo dos bandeirantes, açorianos, portugueses, numa seleção privilegiadora de certos grupos étnicos.

Frente a formação histórica do Rio Grande do Sul duas representações são vinculadas pelos luso-brasileiros em relação ao indígena. A primeira está relacionada à participação deste na constituição do "gaúcho". Este gaúcho, como ressaltam Othelo Rosa e Moysés Vellinho, é ordeiro e sociável ao contrário do "gaúcho malo" platino. Estes autores concluem que no território sul-rio-grandense, o espírito disciplinado e trabalhador do lusitano foi preponderante sobre o espírito instintivo do índio, o mesmo não acontecendo nos países platinos ${ }^{15}$. Portanto, o "selvagem" contribuiu com uma pitada de "espírito de liberdade" e uma boa dose de "ferocidade tribal" indispensáveis para o gaúcho enfrentar os contínuos conflitos fronteiriços.

É nesta disputa de fronteira que se origina a segunda representação: a do índio missioneiro que defende interesses castelhanos e constitui um entrave à civilização luso-brasileira. $\mathrm{O}$ índio missioneiro é retratado como um inimigo que precisa ser combatido e, se preciso, exterminado para que o Estado sulino cumpra seu "destino histórico"16.

Se Moysés Vellinho chegou a expressar dúvidas sobre a humanidade dos indígenas ${ }^{17}$, Carlos Dante de Moraes superou estas dúvidas: o indígena não passava de um degradado e miserável, mero receptáculo onde o invasor cevava o seu instinto ${ }^{18}$.

A argumentação parte sempre da falta, da inexistência de religião, de rei, de lei... O ponto de vista é sempre externo à sociedade do "outro". Não se esboça uma tentativa de compreender as motivações e a dinâmica social deste "outro". Possivelmente, o ambiente intelectual e o lugar social dos discursantes permite um esclarecimento parcial destas visões de mundo. 
O privilegiamento da civilização luso-brasileira e a argumentação baseada no preconceito étnico demonstra a ausência de um projeto que levasse em conta as diferenças étnicas e considerasse a sobrevivência física e a valorização cultural do indígena. Os discursantes refletem a ausência deste projeto e procuram legitimar o etnocídio (o índio é negado para surgir o "gaúcho") ou o genocídio (o índio missioneiro que deve desaparecer por defender interesses alheios à lusitanidade e à brasilidade).

A convergência dos discursos luso-brasileiros se estabelece no uso de categorias como inferioridade, selvageria, atraso civilizatório, incompetência, indolência, rumando para a interpretação pré-estabelecida de que o índio é incapaz de gerir sua própria vida (porém esta incapacidade não acarreta na elaboração de políticas indigenistas de proteção...). Essas posições etnocêntricas são aceitas como sendo naturais e não frutos de uma elaboração intelectual e, portanto, questionáveis e contestáveis.

\section{NOTAS}

1. RUDIGGER, Francisco. Paradigmas do estudo da Historia. Porto Alegre: Instituto Estadual do Livro, 1991, p. 13.

2. TORRES, Luiz Henrique. Historiografia sul-rio-grandense: paradigmas, índios e etnocentrismo". In: Utopia ou barbárie. Rio Grande: Aprofurg, 1992.

3. Entende-se por produção intelectual luso-brasileira a tendência historiográfica cuja diretriz está em demonstrar que o Rio Grande do Sul é legitimamente marcado pela formação portuguesa e desde os primórdios, os rio-grandenses foram antagônicos aos interesses castelhanos. Com variaçōes na abordagem, dando maior ênfase a certos agentes da nacionalidade como os bandeirantes e açorianos, ou até admitindo a importância das Missões e demonstrando simpatias com a obra dos jesuítas, a linha condutora dos estudos está orientada pelo pressuposto de um Rio Grande do Sul que se constituiu na lusitanidade.

4. A defesa do universo luso-brasileiro e açoriano, aparece especialmente nos seguintes trabalhos de João Borges Fortes. A estância. Rio de Janeiro: Tipografia do Ministério da Agricultura, 1931; Casaes. Rio de Janeiro: Editora do Centenário Farroupilha, 1932. Christovão Pereira e a família Fortes. Porto Alegre: Tipografia do Centro, 1932; Troncos Seculares: o povoamento do Rio Grande do Sul. Rio de Janeiro: 1931; Rio Grande de São Pedro. Rio de Janeiro: Bloch, 1941.

5. Consultar Souza Docca: Gente sul-rio-grandense. In: Anais do III Congresso Sul-RioGrandense de História e Geografia. Porto Alegre: Globo, v. II, 1940. História do Rio Grande do Sul. Rio de Janeiro: Organização Simões, 1954.

6. SILVA, João Pinto da. A Provincia de São Pedro. Porto Alegre: Globo, 1930, Historia literária do Rio Grande do Sul. Porto Alegre: Globo, 1930.

7. SPALDING, Walter. À luz da História. Porto Alegre: Globo, 1933; Gênese do Brasil Sul. Porto Alegre: Sulina, 1953. 
8. FORTES, Amyr Borges. Compêndio de História do Rio Grande do Sul. Porto Alegre: Sulina, 1960.

9. ROSA, Othelo. Formação do Rio Grande do Sul. In: Fundamentos da cultura Rio-Grandense. Porto Alegre: Faculdade de Filosofia da Universidade do Rio Grande do Sul, v. II, 1957.

10. VELLINHO, Moysés. Os jesuítas no Rio Grande do Sul" In: Fundamentos da cultura

Rio-Grandense. Porto Alegre: Faculdade de Filosofia da Universidade do Rio Grande do Sul, v. IV, 1960; Formação histórica do gaúcho rio-grandense. In RS Terra e Povo Porto Alegre: Globo, 1960; O gaúcho rio-grandense e o gaúcho platino In: Fundamentos da cultura rio-grandense. Porto Alegre: Faculdade de Filosofia da Universidade do Rio Grande do Sul, v. II, 1957; Capitania d'El Rei: aspectos polêmicos da formação rio-grandense. Porto Alegre: Globo, 1964.

11. PEREIRA FILHO, Arthur. Historia geral do Rio Grande do Sul (1503-1957). Porto Alegre: Globo, 1958.

12. MORAES, Carlos Dante de. Figuras e Ciclos da História Rio-Grandense. Porto Alegre: Globo, 1959.

13. RODRIGUES, Félix Contreiras. Formação social e psicológica do gaúcho brasileiro. In: Anais do I Congresso de História e Geografia Sul-Rio-Grandense. Porto Alegre: Globo, v. I, 1936; Novos Rumos Politicos e Sociais. Porto Alegre: Globo, 1933.

14. TELLES, Norma. A imagem do índio no livro didático equivocada, enganadora. In: SILVA, Aracy Lopes da $A$ questão ind tgena na sala de aula. São Paulo: Brasiliense, 1987, p. 74-5.

15. Ver ROSA, Othelo: Formação do Rio Grande do Sul, op. cit., p. 110 e segs; Moysés Vellinho gaúcho rio-grandense e... op. cit.

16. Ver DOCCA, Souza: Gente sul-rio-grandense, op. cit.; João Borges Fortes. Casaes, op. cit., p. 15; Vellinho Gaúcho riograndense e..., op. cit.

17. VELLINHO, Moysés. Os jesuítas no Rio Grande do Sul, op. cit.

18. MORAES, Carlos Dante de. Figuras e Ciclos..., op. cit., p. 56. 